\title{
Best practice of nurse managers in risk management
}

\author{
Veridiana Tavares Costa ${ }^{1}$ \\ Betina Hörner Schlindwein Meirelles² \\ Alacoque Lorenzini Erdmann ${ }^{3}$
}

Objective: to identify the actions, undertaken by nurse managers in a risk management program, considered as best practice. Method: a case study undertaken in a private hospital in the south of Brazil. A risk manager and nurse managers working in a risk management program participated in this study. The data was collected between May and September 2011 through analysis of documents, semi-structured interviews and non-participant observation. Based on the triangulation, the data was analyzed through practical measures. Results: educational actions, the critical analysis of the context, and the multiple dimensions of the management were evidenced as best practice. Conclusions: the broadening of understanding regarding risk management best practice offers further support for nurse managers to achieve excellence in their actions and thus provide safe and quality care.

Descriptors: Benchmarking; Nursing, Supervisory; Safety Management; Nursing.

${ }^{1}$ Doctoral student, Departamento de Enfermagem, Universidade Federal de Santa Catarina, Florianópolis, SC, Brazil. ${ }^{2} \mathrm{PhD}$, Adjunct Professor, Departamento de Enfermagem, Universidade Federal de Santa Catarina, Florianópolis, SC, Brazil.

${ }^{3} \mathrm{PhD}$, Full Professor, Departamento de Enfermagem, Universidade Federal de Santa Catarina, Florianópolis, SC, Brazil. 


\section{Introduction}

The implantation of quality management systems can bring organizations innumerable benefits, with certification being part of the quest to improve quality ${ }^{(1)}$. The conceptualization of quality in health is held to be complex, which entails the need for understanding on the part of professionals in relation to the logic behind this process ${ }^{(2)}$. Currently, one evaluation tool considered a means of policy guidance in the health systems is hospital accreditation(3).

Quality emerged as a topic for discussion in South America through the Pan-American Health Organization (PAHO) in 1990, when there was discussion regarding what the best actions adopted in the organizations' health practices were, for ensuring quality in the services provided $^{(4)}$, resulting in the term 'best practice'(5).

In line with the definition of the above-mentioned term, best practice allows the recognition of what works best. Furthermore, the adoption of best practice presupposes individual, collective and organizational changes(5-6), with an increase in the credibility of the practice and the capacity to build initiatives. This entails possible benefits, such as the minimization of the risks in the health practices, and the clinical safety of the patient ${ }^{(7-8)}$.

The administration of risks in health was introduced into Brazil in 2001, by the National Health Surveillance Agency (ANVISA), being a recent quality program in health workers' practice and having been extensively discussed in the last few years. This being so, the continuing adoption of new technology in the area of health, in particular in the ambit of Nursing, has led the organizations to implement risk management, thus systematizing the supervision of adverse events with the aim of having greater safety in the actions carried out ${ }^{(9)}$. In Brazil, this is substantiated through the Sentinel Network ${ }^{(10)}$.

The risk management program aims to prevent risk or harm to clients and thus to provide safe, quality care ${ }^{(9)}$. However, it may be noted that patient safety is not totally understood by the nursing professionals, improvement being necessary in their interpretation and understanding regarding this phenomenon ${ }^{(8)}$. In this regard, the adoption of best practice in the ambit of risk management can allow the strengthening of the safety practices.

In the light of these considerations, the following questions emerged: Which actions of nurse managers, in a risk management program, are considered best practice?
Starting from this question, this study aimed to identify the nurse managers' actions, in a risk management program, which were considered as best practice.

\section{Method}

This is a case study, with a qualitative approach, characterized by the use of multiple methods of data collection, aiming to investigate the phenomenon in its multiple aspects ${ }^{(11)}$.

The research setting was a private hospital in the south of Brazil, chosen because the health organization is accredited as part of the Sentinel Hospital Network and also because it has implanted a risk management program. In addition to this, the organization aims to implant Hospital Accreditation in its process. The selection of the participants was undertaken in an intentional form; the inclusion of the nurses who made up the risk management committee was used as an inclusion criteria.

As the study progressed, the necessity was seen for the inclusion of the technical risk manager, because the interviewees emphasized her importance in the effectiveness of the actions which make up the institution's risk management program. This participant, however, has an academic background in economics, but as the manager of the program, it is considered that she has thorough awareness of the nurses' activities in this process. Thus, nine professionals participated in the study: the risk manager, and eight nurse managers, who work in the management and the coordination of nursing, continuous education, the hospital infection control committee and care management.

Data collection took place between May and September 2011, through analysis of documents, semistructured interviews and non-participant observation. The analysis of documents was undertaken over a period of thirty days, during which time the records contained in the risk management plan were evaluated. Following that, in-depth interviews were begun, in which the interviewees spoke freely on the issue, and the investigator sought to deepen their reflections(11). An instrument was used which contained open questions with a focus on the best practice, risk management and quality management. All the interviews were recorded, and then transcribed and typed out in Word.

In addition, the technique of non-participant observation was used, in which were observed the nurse 
managers' actions regarding the occurrence of adverse events, such as falls from beds, phlebitis, the pulling-out of catheters, non-administered medications and adverse reactions to medications. These observations were made in three medical-surgical inpatient units, in the morning and evening shifts. The instrument used at this stage was notes in a field diary, which were later triangulated with the other data.

Data analysis took place through an operational

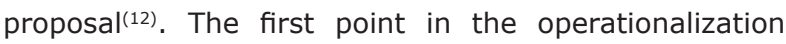
of the data took place through the surveying of the investigation's exploratory phase, which was carried out in three phases:

$1^{\text {st }}$ Phase - Organization of the data, through rereading of material from the notes regarding the risk management plan, the transcription of the interviews recorded, and the organization of the data recorded in the field diary.

$2^{\text {nd }}$ Phase - Classification of the data, undertaken through horizontal and exhaustive reading of the texts with the records of the interviews and the notes in the field diary. Following that, the data was read transversally, separating the units of meaning. The regrouping of these units led to the formulation of three categories, titled: education as best practice in risk management; the critical analysis of the context as best practice in risk management; and, the multiple dimensions of management as best practice in risk management.

$3^{\text {rd }}$ Phase - Final analysis, in which was considered the movement of the empirical and theoretical data for clarification of the phenomenon studied.

The interpretation of the information contained in the multiple sources of evidence used in the collection of the data allowed the case to be studied from a wide variety of angles and thus increased the study's reliability. Based on these results, the data was discussed in relation to the literature researched, with a view to analyzing the best practice of the nurse manager in managing risk.

The study was approved by the Research Ethics Committee of the Federal University of Santa Catarina, under process no 1193/11, meeting the requirements of Resolution n.196/96(13). All the participants were informed regarding the study's objectives, and signed the terms of free and informed consent. So as to maintain confidentiality, the interviewees were assigned codenames (names of flowers) throughout the text. The data will be kept in a secure location by the researchers for five years.

\section{Results}

The results evidenced the educational actions, the critical analysis of the context and the multiple dimensions of the management as best practice of the nurse manager in the managing of risk. These practices will be presented in the categories below, and later, in the discussion of the results.

\section{Education as Best Practice in Risk Management}

The actions identified as continuous education were reported by the participants as being in loco training, supervision, and guidance of the team:

The best practice of the nurse manager is guidance, supervision, and training in loco. (Rose)

In analyzing the notes from the field diary, it was perceived that the above-mentioned actions are focussed on the recording of adverse events, and that after the notification and the acknowledgement of the knowledge of these by the members of the risk management committee, advice is provided, and prevention strategies discussed. Corroborating this, the educational activities mentioned by the participants for the improvement of this process are linked to the importance of the notification of adverse events:

To be monitoring, advising, providing education in loco, so that they may be aware of the importance of the notification of the events, so that we can develop action plans for improvement. (Poppy)

The accounts also emphasize that, in notifying the adverse events, the managers can plan and implement improvement actions, which contributes to the increase in the number of records. This was ratified in analyzing the documents in which were described the graphs of risk management indicators, which indicated yearby-year growth in the number of events notified. The analysis of the indicators reinforces that the integration of risk management culture in the organization is being implanted through educational actions, in spite of this process presenting some limitations:

The only difficulty is getting everybody to understand the importance of managing a risk. (Orchid)

In the light of the documents analyzed, it was confirmed that there are records of three-monthly training sessions provided by the continuing education nurse with the support of the risk management committee. This confirms the implementation of a policy of strengthening the organizational culture for managing hospital risks, evidencing best practice. 
The Critical Analysis of the Context as Best Practice in Risk Management

The written and verbal communication of adverse events through records and notifications was also identified as a practice which supports the investigation of the context and the surveying of the problems, with a view to continuous improvement:

As leader, I have the role of getting them to understand that all the irregularities which they tell me about, to me as boss, I have the autonomy to adjust! I think that the best practice is to record the events, so that we can be in constant improvement. (Tulip)

The reporting and recording of adverse events is perceived by the participants as a practice which contributes to the improvement process, however, in the field observations the existence of sub-notification was perceived, as shown below:

We're sure there's a lot of under-reporting... If the nurse manager went to the sectors more, was nearer, demystifying the issue of punishment and raising the issue of the importance of quality care, he would change the focus and cause there to be more notifications. (Poppy)

The managers noted that the sub-notifications can be related to fear of punishment, because of lack of knowledge on the part of the staff in regard to the objective of the risk management program, as well as to the high staff turnover which exists in the institution. This situation ends up hindering the organizational culture regarding this process:

Our mottois this: this is not about punishing... We only want control, to see how we are doing in this issue of the quality of the service... But it is difficult to overcome the culture in place. (Daisy)

During the non-participant observation, guidance undertaken by some members of the risk management committee was witnessed. Some professionals from the nursing team, on being asked about this program's importance, reported that the communication of adverse events was related to punishment under previous administrations. It is worth emphasizing that some staff had entered the institution recently, this being yet another challenge to the organizational culture and the management of risk:

The staff turnover is very high. This is a hindrance to implementing the plan (Poppy).

In the light of this, the fear of punishment and the high turnover in the team are highlighted as aspects which limit knowledge in relation to the importance of managing risk for quality care. This is all part of understanding the relevance of reporting adverse events as an improvement strategy for minimizing the risks and providing safe, quality care.

\section{The Multiple Dimensions of the Management as Best Practice in Risk Management}

The multiple dimensions of the management are the supervision, the control, the evaluation and the investigation of the processes which surround the recording of adverse events, which were identified as best practice in risk management:

Monitoring, supervision: I see what is happening, I monitor it. (Rose 2)

We are always measuring things, comparing, controlling so as to get a result and aim for improvement... There's no point in us doing the process and not assessing. I think one of the best practices is to be always evaluating, identifying, to change strategies, to improve. (Calla Lily)

We have incorporated the investigation of the events recorded... We have just begun the investigations. Each day we identify the events which were recorded the day before. (Poppy)

The supervision and monitoring of recording of adverse events, in addition to the observation in loco of the actions carried out as a result of said events, guide new practices. Apart from anything else, the evaluation and investigation of this process make it possible to identify shortcomings and direct further actions which allow one to evidence the error and avoid its repetition.

In the field observations, it was also evidenced that in the presence of adverse events, the unit's managers undertook the recording, in accordance with operational flow, and that later quality control would carry out an audit in the area. It is emphasized that this flow of notification of events is available to all staff in either printed or electronic form. Nevertheless, when an event occurs, it is the unit's nurse who usually records it. The information, however, does not always reach her, making it impossible to record. This confirms the presence of sub-notification of the events.

The actions which refer to planning, monitoring, investigating, measuring, supervising and evaluating the processes evidence competences related to the nurses' leadership role in the risk management program. In addition to the actions mentioned, it was also emphasized that for the program to be successful, strategies must be incorporated which avoid the fragmentation of the processes, as this may involve the failure to understand the whole, and, consequently, the failure to resolve the problems: 
In risk management, there is no single manager everybody is responsible. Because, if I fail to report a situation, and cause it not to be taken forward, I delay the problem's solution, and it won't be resolved! (Orchid)

Finally, the existence of the risk management committee, made up of a pharmacist, nurses, a doctor and a risk manager, in conjunction with these professionals' bi-monthly meetings, evidence interdisciplinarity and multidisciplinarity as other dimensions of the management, mentioned as best practice.

\section{Discussion}

Information and quality are among the instruments which indicate the implementation of improvement programs in the ambit of the organizations. The transformations in the world in this new millennium, associated with the competitivity in the organizations, increasingly require the professionals to learn to respond to these new demands ${ }^{(14)}$.

The nurse managers mentioned as best practice the educational practices involving in loco training actions and guidance to the team regarding the relevance of recording adverse events so as to seek improvements in the processes. These practices involve the minimization of risks and strengthen safety practices ${ }^{(15)}$. This evidences that nursing managers concern themselves with adopting strategies which strengthen the involvement of the team in risk management actions.

The communication and recording of adverse events, in being indicated by the nurses as best practice, are contributing to the understanding and strengthening of the safety practices. This may mean changes in the culture of the organization, being associated with this the fact that a change in the culture is necessary in the organizations so as to avoid professional errors, it being necessary to recognize these and to know how they arose ${ }^{(16)}$.

In this regard, the recording of adverse events by the nursing team allows one to develop preventive strategies, thus culminating in better practice. This reinforces that quality is incorporated into the nursing management.

The under-reporting of adverse events, associated with the fear of punishment and the high staff turnover, can limit the effectiveness of the records of these events and the evaluation of the quality. Thus, the culture of patient safety must be strengthened by the hospitals, such that the notification of the events may be confidential and anonymous, avoiding the identification of the responsible or guilty parties so as to discourage under-reporting(17).
One study undertaken with health professionals in accredited institutions evidenced a setting permeated by demands and pressure. It should be emphasized that such a situation may be softened by adding strategies which seek the valorization of the subjects involved, allowing a greater adherence to quality management ${ }^{(14)}$. The participants in the present study seem to be concerned about issues related to the effectiveness of the records for improving the processes, although the need to adopt strategies aiming for this valorization is not clear to them. This can weaken the strengthening of the risk management practices.

The nursing managers have stood out in the health services in the search for quality ${ }^{(18)}$. The technical dimension of this management practice is constituted by planning, coordination, supervision, control and evaluation ${ }^{(19)}$. In this way, supervising, evaluating and controlling the recording of adverse events in a risk management program can be a strong indicator of the assessment of the assistance available for the nurse managers. This confirms that the management is not something isolated, but that it is permeated by multiple dimensions ${ }^{(20)}$.

The existence of a committee for patient safety, made up of a multidisciplinary team and adopting risk analysis methodologies, can be an effective strategy for preventing adverse events; in much the same way, studying the errors so as to avoid their repetition can also be a relevant strategy. In this context, the continuing training of the professionals is emphasized(17), being in line with the nurse manager's best practice as evidenced in this research.

In addition to this, the present research is differentiated in that it incorporates supervision, control, evaluation and investigation of the processes to do with the recording of adverse events. Also added was the importance of strategies which involve multidisciplinarity, interdisciplinarity and the non-fragmentation of the processes for the continuous improvement and excellence of the practice.

In this perspective, it is considered that the best practice as evidenced in this study strengthens the nurses' practice of quality management, given that these practices, integrated in areas such as health, also aim to ensure success in the interventions ${ }^{(21)}$.

\section{Final Considerations}

It was identified that those actions adopted by the nurse managers in the managing of risk which are considered to be the best practice are linked to 
educational actions, the critical analysis of the context, and to the multiple dimensions of the management.

In this context, the authors understand that risk management is linked to the identification of nonconformities in the ambit of the safety processes; proposing preventive actions with the aim of improving the quality of care given and ensuring greater safety to the client. Thus, one may consider that the actions (mentioned here as best practice) strengthen the safety practices in the ambit of the nursing care.

The concern on the part of the nurse managers with ensuring safety in the assistential nursing practice was strongly evident, in the light of the emphasis placed on the recording of adverse events. However, actions of supervision, control, evaluation and investigation of the processes were also emphasized, besides the strategies which involve multidisciplinarity, interdisciplinarity and the non-fragmentation of the processes for the continuous improvement of the practices.

Based on this premise, the identification of risks can allow the nurse manager to implant strategies which culminate in the evaluation of the nursing care. The aim is, therefore, that this study may extend explanation regarding best practice in the management of risk, allowing nurse managers to attain excellence in their actions and thus provide safe and quality care - and in this way to meet the client's needs.

\section{References}

1. Depexe MD, Paladini EP. Benefits of the implementation and certification of quality management systems in construction companies. Rev Gestão Industrial. 2008;4(2): 145-61.

2. Manzo BF, Ribeiro HCTC, Brito MJM, Alves M. Nursing in the hospital accreditation process: practice and implications in the work quotidian. Rev. Latino-Am. Enfermagem. 2012; 20(1):151-8.

3. Fortes MTR, Baptista TWF. Accreditation: tool or policy for health systems organizations? Acta Paul Enferm. [Internet]. 2012 [acesso 4 fev 2013]; 25(4):626-31. Disponível em: http://www.scielo.br/ pdf/ape/v25n4/23.pdf

4. Organização Nacional de Acreditação [Internet]. Brasília: Organização Nacional de Acreditação; c2012 [acesso 10 nov 2011]. Institucional; [4 telas]. Disponível em: http://www.ona.org.br/Inicial.

5. Organização Mundial da Saúde. Procedimentos para a identificação e documentação das melhores práticas. In: Organização Mundial da Saúde . Guia para documentação e partilha das melhores práticas em programas de saúde. Brazzaville: Organização Mundial da Saúde; 2008. p. 16-23.

6. Erdmann AL, Andrade SR, Mello ALSF, Meirelles BHS. Health practice management in the perspective of complex care. Texto Contexto Enferm. 2006; 15(3):483-91.

7. Kahn B, Goodstadt M. The interactive domain model of best practices in health promotion: developing and implementing a best practices approach to health promotion. Health Promotion Practice [Internet]. 2001. [acesso 8 set 2012]; 2(1):43-67. Disponível em: http://www.idmbestpractices.ca/pdf/IDM-HPP.pdf

8. Quez AAM, Montoro CH, Gonzáles MG. Strengths and Threats Regarding the Patient's Safety: Nursing Professionals' Opinion. Rev. Latino-Am. Enfermagem. 2010;18(3):339-45.

9. Kuwabara CCT, Évora YDM, Oliveira MMB. Risk management in technovigilance: construction and validation of a medical-hospital product evaluation instrument. Rev. Latino-Am. Enfermagem. 2010; 18(5): 943-51.

10. Agência Nacional de Vigilância Sanitária [internet]. Rede Sentinela. Brasília: 2012 [acesso 8 set 2012]. Disponível em: http://s.anvisa.gov.br/wps/s/r/jis 11. Mazzoti AJA. Usos e abusos dos estudos de caso. Cad Pesqui. [Internet]. 2006; [acesso $10 \mathrm{fev} \mathrm{2013];}$ 36 (129):637-51. Disponível em: http://www.scielo.br/ pdf/cp/v36n129/a0736129.pdf

12. Minayo MCS. O desafio do conhecimento: pesquisa qualitativa em saúde. São Paulo: Hucitec; 2010.

13. Resolução n. 196, de 10 de outubro de 1996 (BR). Aprova as diretrizes e normas regulamentadoras de pesquisas envolvendo seres humanos. 1996. [acesso 11 jan 2011]. Disponível em: http://conselho.saude.gov. $\mathrm{br} /$ resolucoes/reso_96.htm

14. Cunha ICKO, Ximenes Neto FRG. Managemental abilities of the nurse: the new and old challenge. Texto Contexto Enferm. 2006;15(3):479-82.

15. Manzo BF, Ribeiro HCTC, Brito MJM, Corrêa AR. Implications of hospital accreditation on the everyday lives of healthcare professionals. Rev. Latino-Am. Enfermagem. 2012; 46(2): 388-94.

16. Duarte MM, Silvino ZR. Sistematizando la literatura sobre acreditación hospitalaria: de 2005 a 2010. Enferm Global. [Internet]. 2012; [acesso 29 jan 2013]; 11(1): 299-312. Disponível em: http://dx.doi.org/10.6018/ eglobal.11.1.125421

17. Silva AEBC, Reis AMM, Miasso AI, Santos JO, Cassiani SHB. Adverse drug events in a sentinel 
hospital in the State of Goiás, Brazil. Rev. Latino-Am. Enfermagem. 2011;19(2):378-86.

18. Furukawa PO, Cunha ICKO. Profile and competencies of nurse managers at accredited hospitals. Rev. LatinoAm. Enfermagem. 2011;19(1):106-14.

19. Santos JLG, Garlet ER, Lima, MADS. Systematic review on the management dimension of nursing work in hospital environments. Rev Gaúcha Enferm. 2009;30(3):525-32.

20. Montezeli JH, Peres AM. Nurse's managerial competence: knowledge published in brasilian periodicals. Cogitare Enferm. [Internet]. 2009. [acesso 29 out 2011]; 14(3):553-58. Disponível em: http:// ojs.c3sl.ufpr.br/ojs2/index.php/cogitare/article/ view/16189/10707

21. Organização Mundial da Saúde (AFR). Escritório Regional Africano. Guia para a documentação e partilha das melhores práticas em programas de saúde. Brazzaville: Organização Mundial da Saúde, 2008; [acesso 10 out 2011]; Disponível em: http://afrolib.afro. who.int/documents/2009/pt/GuiaMelhoresPratica.pdf 